\title{
Effects of vegetation restoration on the aggregate stability and distribution of aggregate-associated organic carbon in a typical karst gorge region
}

\author{
F. K. Tang ${ }^{1}$, M. Cui ${ }^{1}$, Q. Lu ${ }^{1}$, Y. G. Liu ${ }^{1}$, H. Y. Guo ${ }^{2}$, and J. X. Zhou ${ }^{2}$ \\ ${ }^{1}$ Institute of Desertification Studies, Chinese Academy of Forestry, Beijing, China \\ ${ }^{2}$ Beijing Forestry University, Key Laboratory of Soil and Water Conservation and Desertification \\ Combating, Ministry of Education, Beijing, China
}

Correspondence to: M. Cui (cuiming2009@foxmail.com)

Received: 27 June 2015 - Published in Solid Earth Discuss.: 7 August 2015

Revised: 5 January 2016 - Accepted: 7 January 2016 - Published: 27 January 2016

\begin{abstract}
Land use changes have a major impact on soil structure and soil nutrients. The influences of vegetation restoration on aggregate stability and soil carbon storage have been studied extensively, but the distribution of aggregate-associated carbon is not yet understood. The objective of this work was to study the influences of vegetation restoration on aggregate stability and distribution of soil organic carbon (SOC) associated with water-stable aggregates (WSAs) in a karst gorge region. The experiment was carried out in 2012 and included four land use types: bare land (BL), grassland (GL), shrubland (SL), and woodland (WL). Soil samples were collected from the 0-20, 2040 , and $40-60 \mathrm{~cm}$ depths, and aggregates were separated by a wet-sieving method. Aggregate stability and aggregatedassociated SOC were determined, and the relationships between water-stable aggregation with SOC were examined. The results showed that total SOC and SOC associated with WSAs of various sizes were the highest at a soil depth of 0$20 \mathrm{~cm}$. In addition, the $\mathrm{SOC}$ contents of the WSAs increased as the soil aggregate sizes decreased. The SOC contents of the WSAs $<0.25 \mathrm{~mm}$ were highest except in the bare land, and the SOC contents of the aggregates $<0.25 \mathrm{~mm}$ comprised the majority of the total aggregate SOC contents. The aggregates were dominated by particles with sizes $>5 \mathrm{~mm}$ under dry-sieving treatment, while aggregates were predominantly comprised of WSAs $<0.25 \mathrm{~mm}$ under wet-sieving treatment. At a soil depth of $0-60 \mathrm{~cm}$, the mean weight diameter (MWD), geometrical mean diameter (GMD), and fractal dimensions $(D)$ of the dry aggregates and water-stable aggre-
\end{abstract}

gates in the different types of land were ranked, in descending order, as $\mathrm{WL}>\mathrm{GL}>\mathrm{SL}>\mathrm{BL}$. The contents of WSAs $>0.25 \mathrm{~mm}, \mathrm{MWD}$, and GMD increased significantly, in that order, and the percentage of aggregate destruction (PAD) and fractal dimensions decreased significantly as the soil aggregate stability improved. SOC contents increased after vegetation restoration, and the average SOC content of WL was 2.35, 1.37, and 1.26 times greater than that in the BL, GL, and SL, respectively. We conclude that woodland and grassland facilitated WSA stability and SOC protection; thus, promoting the natural restoration of vegetation by reducing artificial disturbances could effectively restore the ecology and prevent soil erosion in karst regions.

\section{Introduction}

Soil aggregates are the basic units of soil structures and contribute to soil carbon sequestration function and carbon stabilization (Cerdà, 1996; Mekonnen et al., 2015; Brevik et al., 2015). Good soil structures provide solid foundations for the storage and stabilization of organic carbon (Jastrow, 1996; Mao et al., 2007; Gelaw, 2013). The particle sizes of aggregates affect their abilities to store organic carbon as well as the distributions of their stored organic carbon components (Abu-Hamdeh et al., 2005; Liu and He, 2009). The distribution and stability of soil aggregates is closely related to the erosion resistance of soil and, therefore, are effective indicators of erosion sensitivity (Guo et al., 2007; Rachman et 
al., 2003; Valmis et al., 2005). According to Le Bissonnais $(1996,1997)$, soil erosion is primarily a result of the destruction of soil aggregates. Young (1980) and Bryan (2000) determined that aggregate stability affects the erodibility and nutrient holding capacity of soil. The formation and stability of the water-stable aggregates in soil are dependent on soil organic carbon (SOC), simultaneously vegetation communities affect SOC content via the addition of outer soil organic matter and in turn contribute to the formation of soil aggregates (Gabarrón-Galeote et al., 2013; Mekonnen et al., 2015). Impact of land use changes on aggregate stability and distribution of aggregate-associated SOC have always been research hotspots (Unger, 1997; Dimoyiannis, 2012; Stanchi et al., 2015). Jastrow (1996) researched the formation and stabilization of macroaggregates and process of $\mathrm{C}$ aggradation under different disturbances. Burri et al. (2009) concluded that revegetation measures increased soil aggregate stability by substantially accelerating vegetation development and by promoting soil formation process. Also, Mataix-Solera et al. (2011) found that low-severity fires do not produce notable changes in aggregate stability, but high-severity fires can induce important changes in this property.

China's karst region comprises an area of $3.44 \times 10^{6} \mathrm{~km}^{2}$. The ecosystems that have developed from the karst landforms in this region are characterized by simple ecological community structures, small environmental capacities, and weak resistance to disturbance. These ecologically vulnerable areas are subjected to significant land degradation and stony desertification (Yuan et al., 2002; Yan et al., 2013). The SOC pool is the largest carbon pool in the karst system (Pan and Cao, 1999); the transfer of carbon in the karst system is predominantly controlled by soil carbon. Excessive land utilization and management often result in the destruction of soil structures, the disturbance of the foundations for organic carbon sequestration, the acceleration of soil carbon pool activity, and increased levels of soil erosion (Bai et al., 2013; Tang et al., 2014). Previous studies concerning the stability of soil aggregates and the characteristics of the organic carbon in those aggregates have primarily been conducted in the Loess Plateau (Liu et al., 2013; Qi et al., 2011) and hilly red soil regions (Guo et al., 2007; Yan et al., 2007). Studies regarding the karst region have only recently been conducted in karst plateau (Li et al., 2013) and cluster-peak depression region (Lu et al., 2012). Due to strong karstification, the karst region possesses a unique surface-underground structure and soil erosion different from that in the Loess Plateau and hilly red soil regions, showing that soil leakage underground occurs in addition to soil erosion on the surface (Zhang et al., 2010; Xu, 2014; Yan et al., 2013). Previous studies concerning the distribution of the soil aggregates, aggregate stability, and distribution and mineralization of the organic carbon in the aggregates (Wei et al., 2011; Tan et al., 2014) of the karst region have primarily consisted of single-factor studies. In addition, due to the differences in surface vegetation, litter, and roots resulting from the strong spatial heterogeneity of karst soil, the properties of the soil in different regions vary greatly (Li et al., 2013). Soil degradation in the karst region is characterized by an imbalance of soil aggregate particle composition and a decrease in aggregate stability. Soil erosion and tillage tend to damage water-stable aggregates (WSAs), and fine particles as well as SOC wrapped inside are susceptible to surface water migration loss. Thus, further investigation into changes of SOC content and aggregates stability in process of vegetation degradation/restoration has important theoretical and practical significance in revealing the evolution of soil quality in karst region.

In this paper, the effects of vegetation restoration on aggregates stability and the distribution as well as accumulation of aggregate-associated SOC were analyzed by studying bare land (BL), grassland (GL), shrubland (SL), and woodland (WL), soils typical to the gorge region of the karst plateau in Guizhou Province, China. Furthermore, the influencing mechanism of vegetation restoration on the stability of soil structures and sequestration of organic carbon were investigated in order to provide references concerning the restoration and reconstruction of degenerated karst ecosystems.

\section{Materials and methods}

\subsection{Study area}

The study area was located in the Huajiang Gorge $\left(25^{\circ} 40^{\prime}-\right.$ $25^{\circ} 42^{\prime} \mathrm{N}, 105^{\circ} 37^{\prime}-105^{\circ} 39^{\prime} \mathrm{E}$ ) demonstration area of Guanling County in Guizhou Province, China. This area, located on the eastern slope of the Yunnan-Guizhou Plateau tilting toward the hills in Guangxi, is a typical gorge region on the karst plateau, with an altitude of $500-1200 \mathrm{~m}$ and a relative height difference of $700 \mathrm{~m}$. This region is characterized by a mid-subtropical humid monsoon climate, with sufficient heat, an annual average temperature of approximately $18^{\circ} \mathrm{C}$, and an average annual rainfall of $1200 \mathrm{~mm}$. The typical soils in this area are Calcisol Leptosols according to WRB-based soil classification (IUSS working group, 2015), which are badly structured, dry, and barren.

The zonal vegetation in this area is comprised of midsubtropical broadleaved evergreen forests. Due to the influence of several factors, such as lithology, drought, soil, and human activity, this area has experienced significant levels of vegetative degradation and is characterized by fragile ecosystems and a small environmental carrying capacity. The arbor forests, shrubs, and herbs in this region primarily consist, respectively, of Pteroceltis tatarinowii, Toona sinensis, and Sapium sebiferum; Pyracantha fortuneana, Dodonaea viscosa, Zanthoxylum bungeanum, and Rosa cymosa; and Imperata cylindrica, Arthraxon hispidus, Taraxacum mongolicum, and Dicranopteris dichotoma. Four typical land cover types including BL, GL, SL, and WL were selected for studying the changes of aggregates stability and aggregateassociated SOC in June 2012. The land types were selected 
Table 1. Basic properties of study plots.

\begin{tabular}{|c|c|c|c|c|c|}
\hline $\begin{array}{l}\text { Vegetation } \\
\text { types }\end{array}$ & $\begin{array}{l}\text { Altitude } \\
\text { (ma.s.1.) }\end{array}$ & $\begin{array}{r}\text { Slope } \\
\left({ }^{\circ}\right)\end{array}$ & $\begin{array}{l}\text { Vegetation } \\
\text { cover }(\%)\end{array}$ & $\begin{array}{l}\text { Dominant } \\
\text { species }\end{array}$ & Land use \\
\hline BL & 696 & 20.2 & $<10$ & $\begin{array}{l}\text { Imperata cylindrica and Arthraxon } \\
\text { hispidus }\end{array}$ & $\begin{array}{l}\text { Farmland abandoned } 1 \text { year, with distur- } \\
\text { bance of tillage and pasture }\end{array}$ \\
\hline GL & 710 & 22.1 & 70 & $\begin{array}{l}\text { Imperata cylindrica, Leucas mollis- } \\
\text { sima, and Taraxacum mongolicum }\end{array}$ & $\begin{array}{l}\text { Natural recovery for } 5 \text { years, with less } \\
\text { human disturbance }\end{array}$ \\
\hline SL & 694 & 25.4 & 60 & $\begin{array}{l}\text { Pyracantha fortuneana, Rosa cy- } \\
\text { mosa, and Dodonaea viscosa }\end{array}$ & $\begin{array}{l}\text { Natural recovery for } 9 \text { years, with distur- } \\
\text { bance of pasture }\end{array}$ \\
\hline WL & 704 & 20.0 & 80 & $\begin{array}{l}\text { Toona sinensis, Pteroceltis tatari- } \\
\text { nowii, and Sapium sebiferum }\end{array}$ & $\begin{array}{l}\text { Natural recovery for } 16 \text { years, with less } \\
\text { human disturbance }\end{array}$ \\
\hline
\end{tabular}

based on the topography unit features with similar slope direction, position, bedrock, and vegetation restoration status, also in accordance with the principle of typical and representative. It should be noted that BL, GL, SL, and WL were farmlands before vegetation restoration. The characteristics of the sample plots are shown in Table 1.

\subsection{Sample collection and analysis}

Three research plots with a $20 \mathrm{~m} \times 20 \mathrm{~m}$ horizontal projection area were established for each land cover type. After removing litters from soil surface, undisturbed soil were sampled at depths of 0-20, 20-40, and 40-60 cm by 5-point quincunx sampling method (Zhou, 2003) using a shovel in each research plot. The soil samples of each soil layer from the five points were mixed together as the plot's samples, and a total of 36 mixed soil samples were collected for the purposes of the study. All soil samples were brought back to laboratory and spread flat on kraft papers, broken into $10 \mathrm{~mm}$ clods along their soil cracks, and air-dried indoors.

The separation and water stability of aggregates was determined using the conventional dry-sieving and wet-sieving method (Perfect et al., 1992; Unger, 1997). This method was used to identify the disintegration processes of the soil aggregates under dissipation and expansion (Qi et al., 2011). Firstly, the air-dried soil samples were mixed well, and approximately $1 \mathrm{~kg}$ of soil samples was obtained by quartering and sieving the samples with sieves with mesh sizes of $8,5,2,1,0.5$, and $0.25 \mathrm{~mm}$. Secondly, a total of $100 \mathrm{~g}$ of the dry-sieved aggregates with different size fractions was weighed and placed on sieves with mesh sizes of 5, 2, 1, 0.5 , and $0.25 \mathrm{~mm}$. The soil samples became saturated after being wet for 10 minutes. The soil samples were shaken vertically for $5 \mathrm{~min}$ at an amplitude of $3 \mathrm{~cm}$ and a frequency of 30 times/minute. Finally, the residue on the sieves was collected, dried at $60^{\circ} \mathrm{C}$, and weighed (Sainju et al., 2003). The total SOC and SOC associated with water-stable aggregates were determined through oxidation with potassium dichromate and external heating (Bao, 2005).

\subsection{Data calculation and analysis}

The aggregate stability index (ASI) was determined by transfer matrix method (Shi, 2005). The PAD, mean weight diameter (MWD), and geometrical mean diameter (GMD) were determined by dry-wet sieving method (Yan et al., 2007; He et al., 2011). Since fractal theory can characterize the soil particle distribution and structural features, it has been widely applied to the study of soil structure fractal since the 1980s. Fractal dimension based on the weight distribution were calculated to characterize the distribution and stability of aggregates (Tyler and Wheatcraft, 1989; Yang et al., 1993).

All statistical analyses were performed using Excel 2003 and SPSS 18.0 software. The data conform to normal distribution upon Kolmogorov-Smirnov test (K-S test) and homogeneity of variance test. The one-way analysis of variance (one-way ANOVA) and least significant difference values were used to compare the differences among the various data sets. Pearson's correlation coefficient was used to evaluate the correlations among the different factors. The significance level was defined as $\alpha=0.05$.

\section{Results}

\subsection{Effects of vegetation restoration on total organic carbon and distribution of SOC associated with water-stable aggregates}

The results showed that the organic carbon contents of the aggregates with various particle sizes differed significantly based on the type of vegetation (Fig. 1). The total organic carbon content of the study area ranged from 10.25 to $34.07 \mathrm{~g} \mathrm{~kg}^{-1}$. The organic carbon contents of the soil in the WL, SL, GL, and BL were highest at a soil depth of 0-20 cm and decreased as the soil depth increased. The total organic carbon contents of the various soil layers were ranked, in descending order, as WL > SL > GL > BL.

The contents of SOC associated with water-stable aggregates were different and had no obvious regularity between 


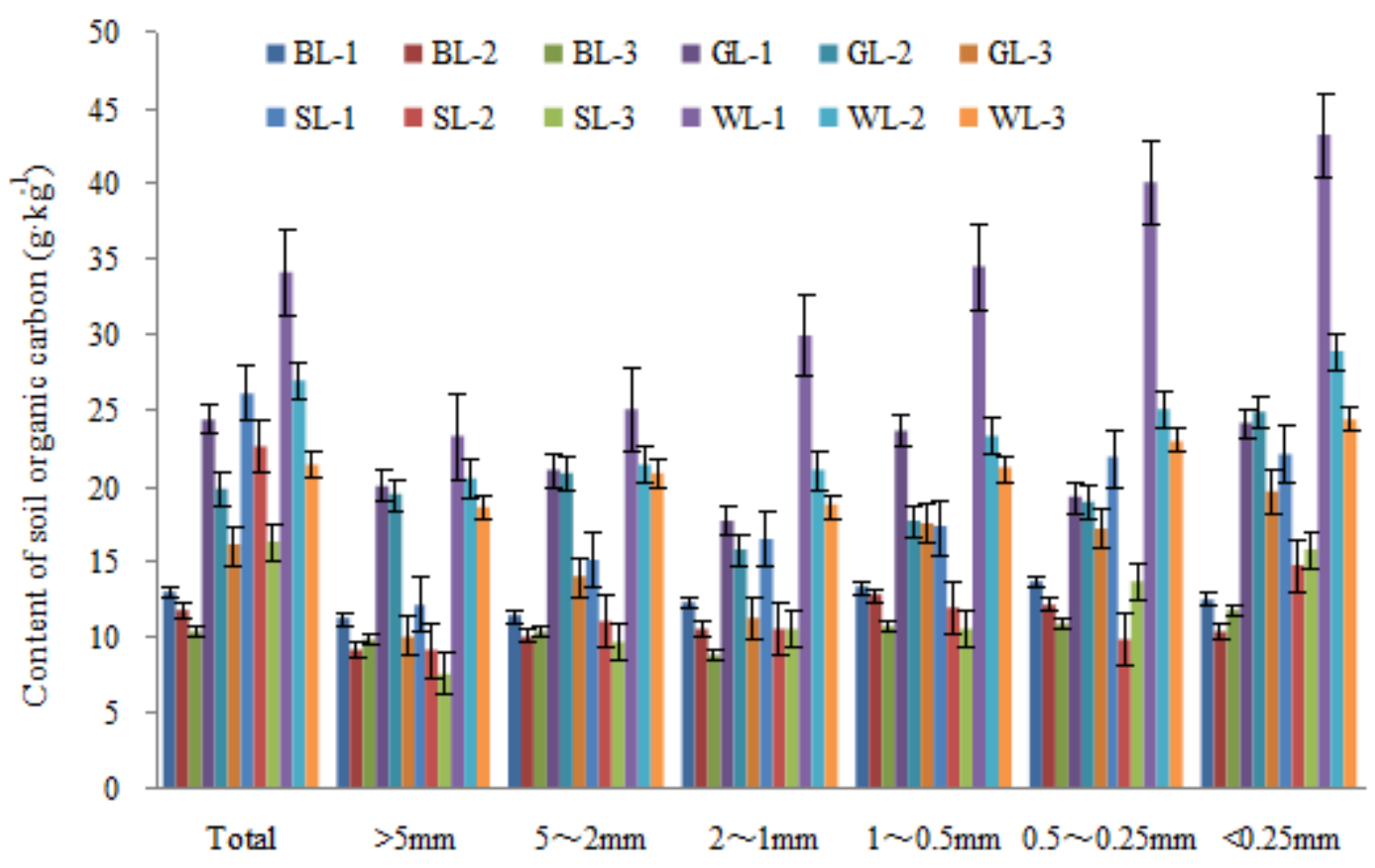

Water stable aggregate sizes

Figure 1. SOC in different water-stable aggregate sizes under different vegetation types (mean \pm SE, $n=3$. BL1, BL2, BL3, GL1, GL2, GL3, SL1, SL2, SL3, WL1, WL2, and WL3 represent 0-20 (1), 20-40 (2), and 40-60 cm (3) soil layers of bare land (BL), grassland (GL), shrubland (SL), and woodland (WL), respectively).

Table 2. Contribution rates of water-stable aggregates organic carbon to SOC under different vegetation types ( $\%$, mean \pm SE, $n=3)$.

\begin{tabular}{|c|c|c|c|c|c|c|c|}
\hline \multirow[b]{2}{*}{$\begin{array}{l}\text { Vegetation } \\
\text { types }\end{array}$} & \multirow[b]{2}{*}{ Layer $\mathrm{cm}^{-1}$} & \multicolumn{6}{|c|}{ WSA sizes $(\%)$} \\
\hline & & $>5 \mathrm{~mm}$ & $5-2 \mathrm{~mm}$ & $2-1 \mathrm{~mm}$ & $1-0.5 \mathrm{~mm}$ & $0.5-0.25 \mathrm{~mm}$ & $<0.25 \mathrm{~mm}$ \\
\hline \multirow[t]{3}{*}{ BL } & $0-20$ & $5.38 \pm 0.33 d$ & $17.68 \pm 0.9 b c$ & $11.6 \pm 1.27 \mathrm{c}$ & $14.82 \pm 1.08 \mathrm{c}$ & $21.19 \pm 0.19 b$ & $25.32 \pm 0.46 \mathrm{a}$ \\
\hline & $20-40$ & $4.92 \pm 0.19 \mathrm{~d}$ & $13.92 \pm 0.31 c$ & $12.65 \pm 0.21 c$ & $16.42 \pm 0.95 b$ & $16.78 \pm 0.16 b$ & $27.88 \pm 1.43 \mathrm{a}$ \\
\hline & $40-60$ & $3.45 \pm 0.20 \mathrm{e}$ & $15.87 \pm 1.05 \mathrm{bc}$ & $13.6 \pm 0.61 c$ & $10.49 \pm 0.56 \mathrm{~d}$ & $19.78 \pm 0.96 b$ & $41.08 \pm 1.81 \mathrm{a}$ \\
\hline \multirow[t]{3}{*}{ GL } & $0-20$ & $7.56 \pm 0.21 b$ & $17.65 \pm 0.57 \mathrm{a}$ & $16.99 \pm 0.38 \mathrm{a}$ & $16.44 \pm 0.45 a$ & $8.55 \pm 0.23 b$ & $18.85 \pm 0.35 a$ \\
\hline & $20-40$ & $2.43 \pm 0.07 \mathrm{~d}$ & $18.45 \pm 0.61 b$ & $22.37 \pm 0.56 \mathrm{a}$ & $18.57 \pm 0.60 b$ & $11.26 \pm 0.31 \mathrm{c}$ & $24.10 \pm 0.50 \mathrm{a}$ \\
\hline & $40-60$ & $2.58 \pm 0.15 d$ & $19.3 \pm 0.95 b$ & $17.04 \pm 0.6 b$ & $17.54 \pm 0.57 b$ & $11.27 \pm 0.34 c$ & $27.72 \pm 0.73 a$ \\
\hline \multirow[t]{3}{*}{ SL } & $0-20$ & $4.24 \pm 0.11 \mathrm{~d}$ & $9.84 \pm 0.29 c$ & $9.28 \pm 0.22 c$ & $9.11 \pm 0.3 c$ & $11.71 \pm 0.15 b$ & $26.51 \pm 0.33 \mathrm{a}$ \\
\hline & $20-40$ & $1.68 \pm 0.10 \mathrm{~d}$ & $6.56 \pm 0.41 c$ & $9.00 \pm 0.34 b$ & $9.56 \pm 0.46 b$ & $7.49 \pm 0.40 c$ & $18.28 \pm 0.65 a$ \\
\hline & $40-60$ & $1.26 \pm 0.05 \mathrm{~d}$ & $7.85 \pm 0.56 c$ & $11.26 \pm 0.42 b$ & $12.44 \pm 0.67 b$ & $11.42 \pm 0.44 b$ & $32.18 \pm 1.06 \mathrm{a}$ \\
\hline \multirow[t]{3}{*}{ WL } & $0-20$ & $16.81 \pm 0.19 b c$ & $17.29 \pm 0.73 b$ & $14.66 \pm 0.19 c$ & $9.39 \pm 0.16 \mathrm{~d}$ & $5.49 \pm 0.62 \mathrm{e}$ & $22.19 \pm 0.20 \mathrm{a}$ \\
\hline & $20-40$ & $16.58 \pm 0.19 b$ & $24.38 \pm 0.78 \mathrm{a}$ & $11.13 \pm 0.21 c$ & $7.78 \pm 0.54 \mathrm{~d}$ & $5.06 \pm 0.11 \mathrm{~d}$ & $20.37 \pm 0.36 \mathrm{a}$ \\
\hline & $40-60$ & $13.91 \pm 0.18 b$ & $24.99 \pm 0.82 \mathrm{a}$ & $16.25 \pm 0.1 b$ & $9.95 \pm 0.40 c$ & $6.43 \pm 0.27 d$ & $26.91 \pm 1.21 \mathrm{a}$ \\
\hline
\end{tabular}

Note: different small letters in the same row indicate significant difference at 0.05 level among different sizes.

different size fractions (Fig. 1). In the BL, the contents of SOC associated with aggregates were relatively high in aggregates with $0.5-1$ and $0.25-0.5 \mathrm{~mm}$ sizes in both $0-20$ and $20-40 \mathrm{~cm}$ soil layer; the SOC of the aggregates $<0.25 \mathrm{~mm}$ was the highest at a soil depth of $40-60 \mathrm{~cm}$. In the GL, SL, and WL, the contents of SOC associated with aggregates
$<0.25 \mathrm{~mm}$ were the highest. The contents of SOC associated with aggregates of all the four kinds of land cover decreased as the decrease of particle sizes. In addition, the contents of SOC associated with aggregates $>5 \mathrm{~mm}$ were the lowest on the whole of all the four land cover types and have significant differences with other particle sizes especially in WL. 
The contents of SOC associated with aggregates were the highest in $0-20 \mathrm{~cm}$ soil layer. In the $\mathrm{BL}$, contents of SOC associated with aggregates decreased with the increase of soil depth except aggregates with $>5,2-1$, and $0.5-0.25 \mathrm{~mm}$ sizes. In the SL, SOC associated with aggregates with 0.50.2 and $<0.25 \mathrm{~mm}$ decreased with the increase of soil depth, and SOC associated with the other aggregate sizes have no obvious regularity with the increase of soil depth. When it comes to GL and WL, the contents of SOC associated with aggregates with various size fractions decreased as the soil depth increased.

As shown in Table 2, in all of the types of land cover, the contribution of the organic carbon in the WSAs $<0.25 \mathrm{~mm}$ to the total organic carbon content of the soil was the highest, ranging from 18.85 to $41.08 \%$, with an average of $25.95 \%$. In the BL, GL, and SL, the contribution of the organic carbon contents of the aggregates $>5 \mathrm{~mm}$ was the lowest with values of less than $10 \%$. In the WL, the contribution of the organic carbon contents of the WSAs with sizes of $0.25-0.5 \mathrm{~mm}$ was the lowest. At different soil depths, the contributions of the organic carbon contents of the WSAs with various sizes to the total organic carbon contents of the aggregates varied insignificantly.

\subsection{Effects of vegetation restoration on distribution of soil aggregate sizes}

The constituent size fractions of the dry-sieved aggregates in the different types of land cover were shown in Fig. 2. The dry-sieved aggregates in the different layers of soil predominantly consisted of aggregates $\geq 2 \mathrm{~mm}$, accounting for greater than $60 \%$ of the total aggregates. The aggregates $>5 \mathrm{~mm}$ also comprised a large amount of the soil aggregates, accounting for $35.56-60.98 \%$ of the total aggregates. The aggregates $<0.25 \mathrm{~mm}$ comprised the smallest proportion of aggregates, accounting for $3.52-8.49 \%$ of the total aggregates. The contents of aggregates from bigger sizes to smaller sizes were gradually diminishing on the whole in each soil depth of different land cover types. Contents of aggregates greater than $5 \mathrm{~mm}$ were showing as $\mathrm{WL}>\mathrm{GL}>\mathrm{SL}>\mathrm{BL}$ in the same soil layer of different land cover, while the other aggregates sizes had no obvious regularity and difference.

For all four land cover types, contents of aggregates $>5 \mathrm{~mm}$ decreased as soil depth increase and aggregates $<0.25 \mathrm{~mm}$ increased as soil depth increase, but the other aggregate sizes had no obvious regularity. Compared with BL, WL, and GL significantly increased the contents of aggregates $>5 \mathrm{~mm}$ and significantly decreased the contents of aggregates $<0.25 \mathrm{~mm}$. Within the different layers of soil, the contents of the aggregates $>5 \mathrm{~mm}$ were ranked, in descending order, as WL $>\mathrm{GL}>\mathrm{SL}>\mathrm{BL}$, and the contents of the aggregates ranging from 2 to $5 \mathrm{~mm}$ were ranked, in descending order, as $\mathrm{SL}>\mathrm{BL}>\mathrm{GL}>\mathrm{WL}$. The contents of the aggregates $<0.25 \mathrm{~mm}$ in the top soil decreased in the vegetation succession from bare land to grassland, shrub land and woodland.

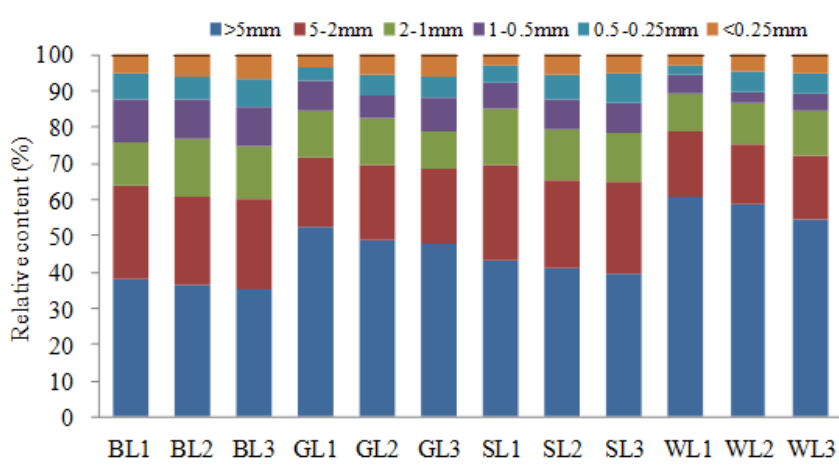

Figure 2. Relative distribution of soil dry aggregates with different sizes under different vegetation types. (BL1, BL2, BL3, GL1, GL2, GL3, SL1, SL2, SL3, WL1, WL2, and WL3 represent 0-20 (1), 2040 (2), and 40-60 cm (3) soil layers of bare land (BL), grassland (GL), shrubland (SL), and woodland (WL), respectively.)

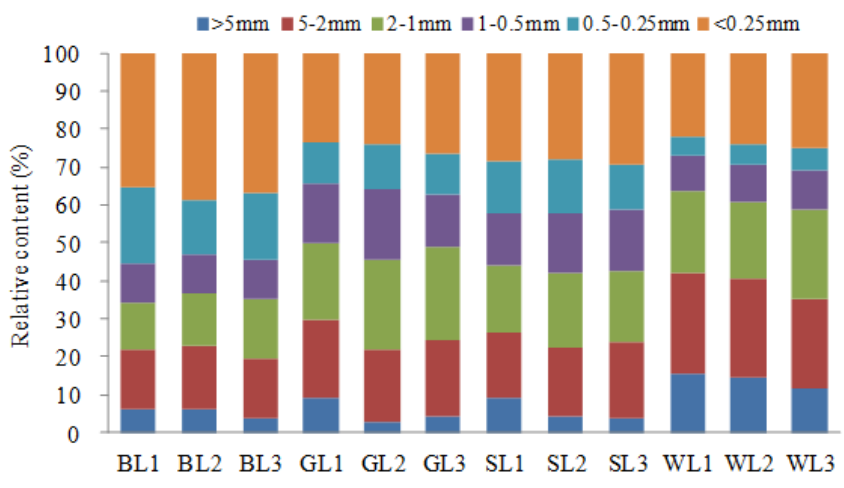

Figure 3. Relative distribution of soil water-stable aggregates with different sizes under different vegetation types (BL1, BL2, BL3, GL1, GL2, GL3, SL1, SL2, SL3, WL1, WL2, and WL3 represent 0-20 (1), 20-40 (2), and 40-60 cm (3) soil layers of bare land (BL), grassland (GL), shrubland (SL), and woodland (WL), respectively).

The water-stable aggregates of the different types of land cover predominantly consisted of particles with sizes $<0.25$, $1-2$, and $2-5 \mathrm{~mm}$, accounting for $59.01-71.31 \%$ of the total WSAs (Fig. 3). Water-stable aggregate contents in BL, GL and SL were minimum in aggregates $>5 \mathrm{~mm}$ and maximum in aggregates $<0.25 \mathrm{~mm}$. When it comes to WL, aggregates content was minimum in aggregates of $0.5-0.25 \mathrm{~mm}$ and maximum in aggregates of 5-2 mm. The WSAs $<0.25 \mathrm{~mm}$ comprised the majority of the total WSAs, accounting for $23.64-35.93 \%$ of the total WSAs. Within the various layers of soil, the content of aggregates $<0.25 \mathrm{~mm}$ in the different types of land use increased as the soil depth increased according to the ranking $\mathrm{BL}>\mathrm{SL}>\mathrm{GL}>\mathrm{WL}$, while the contents of the larger aggregates decreased as the soil depth increased. The BL exhibited the highest content of aggregates $<0.25 \mathrm{~mm}$ in the various layers of soil. The contents of aggregates $<0.25 \mathrm{~mm}$ in the other vegetation types were less than $30 \%$. 
Table 3. The soil aggregate stability based on dry-wet sieving method.

\begin{tabular}{|c|c|c|c|c|c|c|c|c|c|}
\hline \multirow{2}{*}{$\begin{array}{l}\text { Vegetation } \\
\text { types }\end{array}$} & \multirow{2}{*}{$\begin{array}{l}\text { Layer } \\
\mathrm{cm}^{-1}\end{array}$} & \multirow{2}{*}{$\begin{array}{r}\mathrm{WSA}_{>} 0.25 \\
(\%)\end{array}$} & \multirow{2}{*}{$\begin{array}{l}\text { PAD } \\
(\%)\end{array}$} & \multicolumn{2}{|c|}{ MWD (mm) } & \multicolumn{2}{|c|}{ GMD (mm) } & \multicolumn{2}{|c|}{$D$} \\
\hline & & & & Dry & Wet & Dry & Wet & Dry & Wet \\
\hline \multirow[t]{3}{*}{$\mathrm{BL}$} & $0-20$ & $71.68 \mathrm{Ab}$ & $21.5 \mathrm{Cb}$ & 4.183Ad & $1.588 \mathrm{Ac}$ & 3.181 Ac & $0.699 \mathrm{Ac}$ & $2.163 \mathrm{Aa}$ & $2.649 \mathrm{Ba}$ \\
\hline & $20-40$ & $68.21 \mathrm{ABb}$ & $28.34 \mathrm{Ba}$ & 4.085Ad & $1.304 \mathrm{ABc}$ & $2.627 \mathrm{Bd}$ & $0.626 \mathrm{Bc}$ & $2.192 \mathrm{Aa}$ & $2.690 \mathrm{ABa}$ \\
\hline & $40-60$ & $64.07 \mathrm{Bb}$ & $31.87 \mathrm{Aa}$ & $3.243 \mathrm{Bd}$ & $1.169 \mathrm{Bc}$ & $1.966 \mathrm{Cd}$ & $0.535 \mathrm{Cc}$ & $2.227 \mathrm{Aa}$ & $2.725 \mathrm{Aa}$ \\
\hline \multirow[t]{3}{*}{ GL } & $0-20$ & 83.36Aa & $13.59 \mathrm{Cc}$ & $5.335 \mathrm{Ab}$ & $1.966 \mathrm{Ab}$ & $3.882 \mathrm{Ab}$ & $1.061 \mathrm{Ab}$ & $2.037 \mathrm{Aa}$ & $2.487 \mathrm{Bc}$ \\
\hline & $20-40$ & $80.81 \mathrm{Ba}$ & $16.33 \mathrm{Bb}$ & $5.011 \mathrm{ABb}$ & $1.642 \mathrm{Bb}$ & $3.605 \mathrm{ABb}$ & $0.913 \mathrm{Ab}$ & $2.091 \mathrm{Aa}$ & $2.505 \mathrm{ABc}$ \\
\hline & $40-60$ & $74.31 \mathrm{Ca}$ & $19.43 \mathrm{Ac}$ & $4.883 \mathrm{Bb}$ & $1.498 \mathrm{Bb}$ & $3.384 \mathrm{Bb}$ & $0.881 \mathrm{Ab}$ & $2.121 \mathrm{Aa}$ & $2.580 \mathrm{Ac}$ \\
\hline \multirow[t]{3}{*}{ SL } & $0-20$ & $73.86 \mathrm{Ab}$ & $23.13 \mathrm{Ca}$ & 4.655Ac & 1.697Ac & $3.35 \mathrm{Ac}$ & $0.71 \mathrm{Ac}$ & $2.112 \mathrm{Aa}$ & $2.603 \mathrm{Ab}$ \\
\hline & $20-40$ & $68.69 \mathrm{Bb}$ & $26.87 \mathrm{Ba}$ & 4.467Ac & $1.473 \mathrm{ABbc}$ & $3.107 \mathrm{ABc}$ & $0.638 \mathrm{ABc}$ & $2.187 \mathrm{Aa}$ & $2.623 \mathrm{Ab}$ \\
\hline & $40-60$ & $66.5 \mathrm{Bb}$ & $28.26 \mathrm{Ab}$ & 4.415Ac & $1.252 \mathrm{Bc}$ & $2.842 \mathrm{Bc}$ & $0.588 \mathrm{Bc}$ & $2.224 \mathrm{Aa}$ & $2.678 \mathrm{Ab}$ \\
\hline \multirow[t]{3}{*}{ WL } & $0-20$ & 86.72Aa & $10.68 \mathrm{Bd}$ & 6.101Aa & 3.618Aa & $4.934 \mathrm{Aa}$ & $1.981 \mathrm{Aa}$ & $1.994 \mathrm{Aa}$ & $2.425 \mathrm{Bc}$ \\
\hline & $20-40$ & $81.03 \mathrm{Ba}$ & $17.02 \mathrm{Bb}$ & $5.882 \mathrm{Aa}$ & $3.027 \mathrm{Ba}$ & $4.534 \mathrm{Ba}$ & $1.503 \mathrm{Ba}$ & $2.045 \mathrm{Aa}$ & $2.522 \mathrm{ABc}$ \\
\hline & $40-60$ & $76.36 \mathrm{Ca}$ & 21.1Ac & $5.41 \mathrm{Ba}$ & $2.505 \mathrm{Ba}$ & $4.087 \mathrm{Ca}$ & $1.151 \mathrm{Ca}$ & $2.074 \mathrm{Aa}$ & $2.556 \mathrm{Ac}$ \\
\hline
\end{tabular}

Note: different small letters in the same column mean significant differences in same layer of different land cover types at 0.05 level; different capital letters in the same column mean significant differences in different soil layer of same land cover types at 0.05 level, the same in the Table 4 .

\subsection{Effects of vegetation restoration on soil aggregate stability}

The stability of the soil aggregates differed significantly based on the type of vegetation (Table 3). The soil depth also affected the stability of the soil aggregates. The contents of the aggregates $>0.25 \mathrm{~mm}$ in the WL, GL, SL, and BL, were equal to $81.37,79.49,69.02$, and $68.65 \%$, respectively. The PAD of the aggregates $>0.25 \mathrm{~mm}$ in the BL $(27.24 \%)$ was the highest, and the PAD of the aggregates $>0.25 \mathrm{~mm}$ in the WL (16.27\%) was the lowest. The MWD and GMD values of the dry-sieving and wet-sieving aggregates were both ranked, in descending order, as $\mathrm{WL}>\mathrm{GL}>\mathrm{SL}>\mathrm{BL}$. The fractal dimensions of the dry-sieved aggregates in the four types of land cover ranged from 1.994 to 2.227, and the fractal dimensions of the WSAs ranged from 2.425 to 2.725, ranking, in descending order, as $\mathrm{BL}>\mathrm{SL}>\mathrm{GL}>\mathrm{WL}$ in studied soil profile.

In all four types of land cover, the contents of the aggregates $>0.25 \mathrm{~mm}$, MWD, and GMD decreased with the increase of soil depth. Contrarily, the PAD and D values increased as the soil depth increased. The MWD and GMD of the dry-sieved and wet-sieved aggregates were ranked, in descending order, as $\mathrm{WL}>\mathrm{GL}>\mathrm{SL}>\mathrm{BL}$, while the $\mathrm{D}$ values of the dry-sieving and wet-sieving aggregates were ranked, in descending order, as $\mathrm{BL}>\mathrm{SL}>\mathrm{GL}>\mathrm{WL}$. The PAD of the aggregates obtained at a soil depth of $0-20 \mathrm{~cm}$ were ranked, in descending order, as $\mathrm{SL}>\mathrm{BL}>\mathrm{GL}>\mathrm{WL}$, while the PAD of the aggregates obtained at soil depths of 20-40 and 40-60 cm were ranked, in descending order, as $\mathrm{BL}>\mathrm{SL}>\mathrm{WL}>\mathrm{GL}$. The stability of the soil aggregates in the same soil layers of the different types of vegetation was significantly different. Other indicators changed not significantly as the soil depth changed.
The probabilities of the soil aggregates in the different types of land cover remaining unchanged are shown in Table 4. In the BL, GL, and SL, dry-sieving and wet-sieving destroyed the aggregates with particle sizes greater than $5 \mathrm{~mm}$ and ranging from 1 to $5 \mathrm{~mm}$ and a have small impact on the aggregates with sizes ranging from 0.25 to $1 \mathrm{~mm}$. The probability of the soil aggregates with sizes ranging from 0.25 to $1 \mathrm{~mm}$ remaining unchanged ranged from 0.26 and 0.51 . In the WL soil, the probability of the soil aggregates $>5 \mathrm{~mm}$ remaining unchanged was the highest $(0.39-0.55)$, and the probability of the soil aggregates with sizes ranging from 0.25 to $0.5 \mathrm{~mm}$ only ranged from 0.23 to 0.31 . The ASI values ranged from 2.19 to 3.32 . The average ASI values of the WL, GL, SL, and BL were, in descending order, equal to $2.85,2.65,2.39$, and 2.31, respectively. The ASI values of the aggregates in the topsoil were the highest, and the ASI values decreased as the soil depth increased. The ASI values of the different types of land cover at different soil depths were ranked, in descending order, as WL > GL > SL > BL. The difference of the ASI values between WL and GL, as well as BL and SL were not significant at the same soil layer. However, except at soil depths of $20-40$ and $40-60 \mathrm{~cm}$, the differences in the ASI values of the GL and BL and the values of WL and SL at the same soil depths were significant.

\subsection{Relationships between water-stable aggregates and organic carbon}

The correlations among the parameters of the WSAs are shown in Table 5. Fractal dimension was significantly and negatively associated with the MWD, GMD, and SOC $(P<0.01)$, and the MWD was significantly and positively associated with the GMD $(P<0.01)$. The SOC was significantly and positively associated with both the MWD and GMD $(P<0.01)$. The contents of the aggregates with par- 
Table 4. Conservation ratio of aggregates and aggregate stability index.

\begin{tabular}{|c|c|c|c|c|c|c|c|c|}
\hline \multirow{2}{*}{$\begin{array}{l}\text { Vegetation } \\
\text { types }\end{array}$} & \multirow{2}{*}{$\begin{array}{l}\text { Layer } \\
\mathrm{cm}^{-1}\end{array}$} & \multicolumn{6}{|c|}{ Conservation ratio of aggregates $(\%)$} & \multirow[b]{2}{*}{$\begin{array}{r}\text { Aggregate stability } \\
\text { index (ASI) }\end{array}$} \\
\hline & & $>5 \mathrm{~mm}$ & $5-2 \mathrm{~mm}$ & $2-1 \mathrm{~mm}$ & $1-0.5 \mathrm{~mm}$ & $0.5-0.25 \mathrm{~mm}$ & $<0.25 \mathrm{~mm}$ & \\
\hline \multirow[t]{3}{*}{ BL } & $0-20$ & 0.22 & 0.25 & 0.28 & 0.3 & 0.42 & 1 & $2.47 \mathrm{Ab}$ \\
\hline & $20-40$ & 0.15 & 0.28 & 0.23 & 0.28 & 0.38 & 1 & $2.30 \mathrm{Bb}$ \\
\hline & $40-60$ & 0.10 & 0.23 & 0.21 & 0.26 & 0.39 & 1 & $2.19 \mathrm{Bb}$ \\
\hline \multirow[t]{3}{*}{ GL } & $0-20$ & 0.18 & 0.34 & 0.44 & 0.46 & 0.49 & 1 & $2.91 \mathrm{Aa}$ \\
\hline & $20-40$ & 0.05 & 0.24 & 0.38 & 0.42 & 0.51 & 1 & $2.60 \mathrm{Ba}$ \\
\hline & $40-60$ & 0.07 & 0.31 & 0.32 & 0.36 & 0.39 & 1 & $2.45 \mathrm{Ba}$ \\
\hline \multirow[t]{3}{*}{ SL } & $0-20$ & 0.19 & 0.28 & 0.26 & 0.34 & 0.44 & 1 & $2.51 \mathrm{Ab}$ \\
\hline & $20-40$ & 0.09 & 0.21 & 0.25 & 0.34 & 0.45 & 1 & $2.34 \mathrm{Bb}$ \\
\hline & $40-60$ & 0.07 & 0.22 & 0.22 & 0.35 & 0.46 & 1 & $2.32 \mathrm{Bb}$ \\
\hline \multirow[t]{3}{*}{ WL } & $0-20$ & 0.55 & 0.51 & 0.52 & 0.43 & 0.31 & 1 & $3.32 \mathrm{Aa}$ \\
\hline & $20-40$ & 0.48 & 0.35 & 0.30 & 0.31 & 0.25 & 1 & $2.69 \mathrm{Ba}$ \\
\hline & $40-60$ & 0.39 & 0.23 & 0.38 & 0.30 & 0.23 & 1 & $2.53 \mathrm{Ba}$ \\
\hline
\end{tabular}

ticle sizes of greater than 5, 2-5, and 1-2 mm were significantly and negatively correlated with $\mathrm{D}(P<0.05)$, and the contents of the aggregates with particle sizes of $0.25-0.5 \mathrm{~mm}$ and less than $0.25 \mathrm{~mm}$ were significantly and positively correlated with D $(P<0.05)$. The MWD and GMD were significantly and positively correlated with the contents of the aggregates $>2 \mathrm{~mm}$ and significantly and negatively correlated with the contents of the aggregates $<0.5 \mathrm{~mm}$. The SOC was positively correlated with the contents of aggregates with various size fractions and significantly correlated with the contents of aggregates greater than $5 \mathrm{~mm}$.

\section{Discussion}

\subsection{Effects of vegetation restoration types on distribution of SOC associated with water-stable aggregates}

The SOC contents of soil aggregates with various particle sizes can be used to micro-characterize the balance between organic matter and the mineralization rate of organic carbon. The organic carbon contents of aggregates affect the nutrient holding capacity and carbon sequestration in soil significantly (Wu et al., 2004). The soil organic matters of different land use types differed based on the quantity and quality of the litter and the environment, affecting the organic carbon contents of the soil and the stability and contents of the organic carbon in the aggregates (Novara et al., 2015). In all four types of land cover, the SOC contents associated with aggregates with various particle sizes were the highest at a soil depth of 0-20 cm, which were consistent with the results of Li et al. (2002). This was because the large amount of plant residue that had accumulated in the topsoil and the amount of organic matter that had been input into the soil improved the biological activity of the microorganisms, animals, and roots in the topsoil and, thus, facilitated the formation of particulate organic carbon (Wei et al., 2011).

Vegetation restoration have great impact on the contents of total SOC and SOC associated with different aggregate sizes. The organic carbon contents of the aggregates were the highest in the WL and the lowest in the SL and BL, primarily due to the amount of vegetative coverage and the quantity and decomposition of litter. Due to their high amounts of vegetative coverage, the WL and GL exhibited large amounts of litter and a considerable amount of input SOC. The BL and SL exhibited significantly smaller amounts of litter and input SOC and accelerated levels of organic carbon decomposition due to artificial disturbances. In general, the organic carbon contents of the soil aggregates decreased as the soil depth increased; in these types of land cover, artificial disturbances accelerated the decomposition of organic carbon.

In previous studies, De Jonge (1999), Christensen (1986), and $\mathrm{Li}$ et al. (2006) determined that organic carbon is primarily distributed in microaggregates $(<0.25 \mathrm{~mm})$ and that organic carbon contents increase as aggregate particle sizes decrease. Puget $(1998,2000)$ found that large aggregates are a source of organic carbon enrichment. In another study, Li et al. (2000) found that organic carbon is distributed in a " $V$ " shape in aggregates and that the organic carbon contents of aggregates $>2 \mathrm{~mm}$ and $<0.25 \mathrm{~mm}$ are high. In a study by $\mathrm{Li}$ et al. (2000), as the particle sizes increased the SOC contents decreased, but the organic carbon contents of the aggregates exhibited no significant differences, possibly due to the high calcium carbonate and clay contents of the lime soil in the karst region (Wei et al., 2011). In this study, the organic carbon contents of the aggregates $<0.25 \mathrm{~mm}$ in the GL, SL, and WL increased by 5.28-95.37, 1.46-106.25, and 6.02$85.43 \%$ compared to the aggregates with other particle sizes. These results corresponded with the theory that organic carbon initially accumulates in aggregates with small size frac- 
Table 5. Correlation between parameters of water-stable aggregation.

\begin{tabular}{|c|c|c|c|c|c|c|c|c|c|c|c|}
\hline & & \multirow[b]{2}{*}{$D$} & \multirow[b]{2}{*}{ MWD } & \multirow[b]{2}{*}{ GMD } & \multirow[b]{2}{*}{ SOC } & \multicolumn{6}{|c|}{ WSA sizes $(\mathrm{mm})$} \\
\hline & & & & & & $>5$ & $5-2$ & $2-1$ & $1-0.5$ & $0.5-0.25$ & $<0.25$ \\
\hline$D$ & & 1 & & & & & & & & & \\
\hline MWD & & $-0.544^{* *}$ & 1 & & & & & & & & \\
\hline GMD & & $-0.608^{* *}$ & $0.963^{* *}$ & 1 & & & & & & & \\
\hline \multirow[t]{3}{*}{ SOC } & & $-0.454^{* *}$ & $0.701^{* *}$ & $0.756^{* *}$ & 1 & & & & & & \\
\hline & $>5$ & -0.203 & $0.409^{*}$ & 0.265 & $0.588^{* *}$ & 1 & & & & & \\
\hline & $5-2$ & $-0.346^{*}$ & 0.168 & 0.203 & $0.348^{*}$ & $0.798^{* *}$ & 1 & & & & \\
\hline WSA & $2-1$ & -0.202 & 0.224 & 0.121 & $0.418^{*}$ & $0.871^{* *}$ & $0.808^{* *}$ & 1 & & & \\
\hline sizes & $1-0.5$ & -0.215 & 0.194 & 0.172 & $0.410^{*}$ & $0.882^{* *}$ & $0.817^{* *}$ & $0.951^{* * *}$ & 1 & & \\
\hline \multirow[t]{2}{*}{$(\mathrm{mm})$} & $0.5-0.25$ & $0.312^{*}$ & 0.114 & 0.237 & $0.338^{*}$ & $0.822^{* *}$ & $0.678^{* *}$ & $0.947^{* *}$ & $0.926^{* *}$ & 1 & \\
\hline & $<0.25$ & $0.633^{* *}$ & 0.074 & 0.112 & $0.368^{*}$ & $0.865^{* *}$ & $0.835^{* *}$ & $0.960^{* *}$ & $0.922^{* *}$ & $0.951^{* *}$ & 1 \\
\hline
\end{tabular}

${ }^{*} P<0.05 ; * *<<0.01$.

tions (Hassink, 1997) as well as the results of other studies concerning the karst region (Lu et al., 2012; Luo et al., 2011).

\subsection{Effects of vegetation restoration on the distribution and stability of soil aggregates}

The size fractions of aggregates affect the storage and supply of soil nutrients, the pore structure and hydraulic properties of soil, and the movement of organisms in soil. Therefore, the size distributions of aggregates are closely related to soil quality (Dexter, 1988; Nimmo and Perkins, 2002). SOC is a binding substance imperative for the formation of aggregate structures (Cerdà, 2000; Wu et al., 2004). Land cover significantly affects SOC contents by influencing the input and output of the organic matter in soil and, therefore, the distribution and stability of soil aggregates (Powers, 2004; Luo et al., 2011; Arjmand et al., 2015). After vegetation restoration, the organic carbon contents, MWD, and GMD of the WSAs $>0.25 \mathrm{~mm}$ increased, and the PAD and D values decreased. Thus, as a result of vegetation restoration, the SOC content increased, promoting the formation of soil aggregates and increasing the stability of the soil aggregates. The organic carbon contents, MWD, and GMD of the WSAs $>0.25 \mathrm{~mm}$ in the WL and GL were significantly higher than those of the WSAs $>0.25 \mathrm{~mm}$ in the BL and SL, while the PAD values of the WL and GL were significantly lower than those of the BL and SL, indicating that the WL and GL possessed good soil aggregate structures with strong resistance and high nutrient storage capacities. In the BL and SL, artificial disturbances led to the destruction of soil structures, accelerating the transformation of large WSAs to aggregates with small size fractions and exacerbating the low of soil and nutrients. The structural stability and erosion resistance of the soil in the GL were higher than those of the soil in the SL, primarily because the GL was subjected to less disturbances. Thus, the GL exhibited higher levels of vegetative coverage with considerable amounts of returned biomass, while the SL, due to felling, picking, and the forced compaction of wildlife, pos- sessed fewer soil organic matter sources and disrupted soil structures. BL and SL were prone to erosion when they suffered strong rainfall splash due to low surface vegetation coverage, leading to aggregates dispersed into small ones and decomposition of unstable organic carbon, which result in a substantial decline in macroaggregates and organic carbon content (Gabarrón-Galeote et al., 2013).

The contents of the WSAs decreased as the soil depth increased. This was likely because the excess litter on the topsoil; the high organic matter contents; and the good water, heat, and air conditions of the soil contributed to the formation of large aggregates (Tisdall and Oades, 1982; Xiao et al., 2008). In addition, the organic matter contents of the deep soil were relatively low, a small number of large soil aggregates were formed, and the contents of the large WSAs were reduced. In the same types of land cover, the ASI of the WSAs decreased as the soil depth increased, just as the contents of the large WSAs decreased as the soil depth increased. Of the four typical types of land cover in the study area, the WL exhibited the highest aggregate stability and strongest erosion resistance, promoting the stability of the soil structure, the storage of nutrients, and the contents of organic carbon. The GL soil exhibited the second highest aggregate stability, and the BL and SL possessed relatively poor water stability.

The vegetation restoration process significantly affected the formation and distribution of large aggregates in that the BL, SL, GL, and WL exhibited significantly decreased levels of aggregates $<0.25 \mathrm{~mm}$ throughout the various soil layers and significantly increased levels of larger aggregates throughout the vegetation restoration process. Studies have shown that vegetation restoration would effectively improve the soil infiltration capacity, water holding capacity, and aeration of the lime soils and promote the formation of soil aggregates (Qi, 2007). Therefore, aggregate stability could be improved and soil erosion could be prevented by reducing soil disturbances, increasing the organic matter and nutrient con- 
tents of soil, and, therefore, facilitating the natural restoration of vegetation.

The fractal dimensions of the particle size distributions of soil granular structures reflect the influence of the contents of aggregates on the structure and stability of the soil (Dexter, 1988; Nimmo and Perkins, 2002). Thus, smaller fractal dimensions indicate better soil structures and stability and higher erosion resistance. Likewise, higher fractal dimensions indicate poorer soil structures and stability (Zhou et al., 2008; Barral et al., 1998).

The fractal dimensions of various soil particle sizes reflect the ability of the soil particles to fill spaces and could be used to evaluate soil structures (Tyler and Wheatcraft, 1989; Yang et al., 1993). According to the correlation analysis, D was significantly positively correlated with aggregates $<0.25 \mathrm{~mm}$ and had significantly negative correlations with MWD, GMD, and SOC. As the value of D increased, the contents of the aggregates $>0.25 \mathrm{~mm}$ decreased, and the soil density increased; this may result in poorer permeability as well as nutrient and moisture storage capacities. The results of this study indicated that as the vegetation was restored, the fractal dimensions of the WSAs decreased, and the stability of the soil structures and organic carbon contents improved.

\section{Conclusions}

Total SOC and SOC associated with water-stable aggregates increased with the restoration of vegetation. SOC was initially accumulated in aggregates with small size fractions and WSAs $<0.25 \mathrm{~mm}$ has the greatest contribution to soil total SOC. Contents of WSAs $<0.25 \mathrm{~mm}$ reduced while WSAs $>1 \mathrm{~mm}$ increased significantly in the process of vegetation succession from bare land to woodland. Vegetation restoration has promoted the accumulation of aggregates with small particle sizes into large sizes and, therefore, improved water stability of aggregates. The fractal dimension of water-stable aggregates was highly significantly and negatively correlated with the MWD, GMD, and SOC $(P<0.01)$, indicating that it could be used to objectively and comprehensively reflect the soil aggregate characteristics and stability. The woodland and grassland were more conducive to facilitate water-stable aggregate stability and SOC protection; thus, promoting natural vegetation restoration by reducing artificial disturbances could effectively restore the ecology and prevent soil erosion in karst regions.

Acknowledgements. We gratefully acknowledge the editor and reviewers. This research was financially supported by the fundamental research funds for the Central Non-profit Research Institution of CAF (CAFYBB2014ZD006). Thanks to S. Yan, G. J. Li and W. Zhou for their assistances with the fieldwork and lab measurements.

Edited by: P. Pereira

\section{References}

Abu-Hamdeh, N. H., Abo-Qudais, S. A., and Othman, A. M.: : Effect of soil aggregate size on infiltration and erosion characteristics, Eur. J. Soil Sci., 5, 609-616, 2005.

Arjmand Sajjadi, S. and Mahmoodabadi, M.: Aggregate breakdown and surface seal development influenced by rain intensity, slope gradient and soil particle size, Solid Earth, 6, 311-321, doi:10.5194/se-6-311-2015, 2015.

Bao, S. D.: Soil and Agricultural Chemistry Analysis, China Agriculture Press, Beijing, 2005.

Bai, X. Y., Wang, S. J., and Xiong, K. N.: Assessing spatialtemporal evolution processes of karst rocky desertification land: indications for restoration strategies, Land Degrad. Develop., 24, 47-56, 2013.

Barral, M. T., Arias, M., and Guerif, J.: Effects of iron and organic matter on the porosity and structural stability of soil aggregates, Soil Till. Res., 3, 261-272, 1998.

Brevik, E. C., Cerdà, A., Mataix-Solera, J., Pereg, L., Quinton, J. N., Six, J., and Van Oost, K.: The interdisciplinary nature of soil, Soil, 1, 117-129, 2015.

Bryan, R. B.: Soil erodibility and processes of water erosion on hill slopes, Geomorphology, 32, 385-415, 2000.

Burri, K., Frank G., and Albert, B.: Revegetation measures improve soil aggregate stability: a case study of a landslide area in Central Switzerland, For. Snow Landsc Res., 1, 45-60, 2009.

Cerdà, A.: Soil aggregate stability in three mediterranean environment, Soil Technol., 9, 129-133, 1996.

Cerdà, A.: Aggregate stability against water forces under different climates on agriculture land and scrubland in southern Bolivia, Soil Till. Res., 36, 1-8, 2000.

Christensen, B. T.: Straw incorporation and soil organic matter in macro aggregates and particle size separates, Eur. J. Soil Sci., 37, 125-135, 1986.

De Jonge, L. W., Jacobsen, O. H., and Moldrup, P.: Soil water repellency effects of water content, temperature and particle size, Soil Sci. Soc. Am. J., 63, 437-44, 1999.

Dexter, A. R.: Advances in characterization of soil structure, Soil Till. Res., 11, 199-238, 1988.

Dimoyiannis, D.: Wet aggregate stability as affected by excess carbonate and other soil properties, Land Degrad. Develop., 23, 450-455, 2012

Gabarrón-Galeote, M. A., Martínez-Murillo, J. F., Quesada, M. A., and Ruiz-Sinoga, J. D.: Seasonal changes in the soil hydrological and erosive response depending on aspect, vegetation type and soil water repellency in different Mediterranean microenvironments, Solid Earth, 4, 497-509, doi:10.5194/se-4-497-2013, 2013.

Gelaw, A. M., Singh, B. R., and Lal, R.: Organic carbon and nitrogen associated with soil aggregates and particle sizes under different land uses in Tigray, Northern Ethiopia, Land Degrad. Develop., 7, 690-700, doi:10.1002/ldr.2261, 2013.

Guo, W., Shi, Z. H., Chen, L. D., Li, C. X., Yan, L. F., and Cai, C. F.: Effects of topsoil aggregate size on runoff and erosion at hillslope in red soils, Acta Ecologica Sinica, 6, 2516-2522, 2007.

Hassink, J.: The capacity of soils top reserve organic $\mathrm{C}$ and $\mathrm{N}$ by their association with clay and silt particles, Plant Soil, 1, 77-87, 1997.

He, S. Q., Zheng, Z. C., and Gong, Y. B.: Distribution characteristics and soil organic carbon of soil water-stable aggregates with 
different de-farming patterns, J. Soil Water Conserv., 5, 229-233, 2011.

IUSS Working Group: World Reference Base for Soil Resources 2014, World Soil Resources Reports, FAO, No. 106, 2015.

Jastrow, J. D.: Soil aggregates formation and the accrual of particulate and mineral-associated organic matter, Soil Biol. Biochem., 28, 656-676, 1996.

Le Bissonnais, Y.: Aggregate stability and assessment of soil crushability and erodibility I: Theory and methodology, Eur. J. Soil Sci., 47, 425-435, 1996.

Le Bissonnais, Y. and Arrouays, D.: Aggregate stability and assessment of soil crustability and erodibility II: Application to humic loamy soils with various organic carbon contents, Eur. J. Soil Sci., 48, 39-48, 1997.

Li, H. X., Yuan, Y. H., Huang, Q. R., Hu, F., and Pan, G. X.: Effects of fertilization on soil organic carbon distribution in various aggregates of red paddy soil, Acta Pedologica Sinica, 3, 422-428, 2006.

Li, J., Liao, H. K., Long, J., and Chen, C. Y.: Effect of land use on the characteristics of organic carbon and labile organic carbon in soil aggregates in Karst mountain areas, Acta Ecologica Sinica, 7, 2147-2156, 2013.

Li, L. Q., Pan, G. X., and Zhang, X. H.: Changes in organic carbon storage in aggregates of the surface horizon in a degraded Paleudlt upon vegetation recovery, Chinese J. Soil Sci., 5, 193195, 2000.

Li, Y. B., Xie, D. T., Wei, C. F., and Zhou, B. T.: A study of features of water-stable soil aggregate structure under different land use in karst mountains, Resoyrces and Anvironment in the Yangtza Basin, 5, 451-455, 2002.

Liu, L., An, S. S., and Huang, H. W.: Application of Le Bissonnais method to study soil aggregate stability under different vegetation on the loess plateau, Acta Ecologica Sinica, 20, 6670-6680, 2013.

Liu, X. L. and He, Y. Q.: Water-Stable Aggregates and Nutrients in Red Soil Under Different Reclamation Years, Soils, 1, 84-89, 2009.

Lu, L. X., Song, T. Q., Peng, W. X., Zeng, F. P., Wang, K. L., and $\mathrm{Xu}$, Y. L.: Profile distribution of soil aggregates organic carbon in primary forests in Karst cluster-peak depression region, Chinese Journal of Applied Ecology, 5, 1167-1174, 2012.

Luo, Y. J, Wei, C. F., Li, Y., Ren, Z. J., and Liao, H. P.: Effects of land use on distribution and protection of organic carbon in soil aggregates in Karst rocky desertification area, Acta Ecologica Sinica, 1, 257-266, 2011.

Mao, Y. L., Yang, Y. S., Zou, S. Q., Chen, G. S., and Wang, G. Q.: Effects of Land Use on Soil Organic Carbon in Aggregates of Hilly Red Soil in Subtropical China, J. Mountain Sci., 6, 706713, 2007.

Mataix-Solera, J., Cerdà, A., Arcenegui, V., Jordán, A., and Zavala, L. M.: Fire effects on soil aggregation: a review, Earth Sci. Rev., 1, 44-60, 2011.

Mekonnen, M., Keesstra, S. D., Stroosnijder, L., Baartman, J. E. M., and Maroulis, J.: Soil conservation through sediment trapping: a review, Land Degrad. Develop., 26, 544-556, doi:10.1002/ldr.2308, 2015.

Nimmo, J. R. and Perkins, K. S.: Aggregate stability and size distribution, in: Methods of Soil Analysis, Part 4: Physical Methods, edited by: Dane, J. H. and Topp, G. C., Madison, WI: Soil Science Society of America, 317-328, 2002.

Novara, A., Rühl, J., La Mantia, T., Gristina, L., La Bella, S., and Tuttolomondo, T.: Litter contribution to soil organic carbon in the processes of agriculture abandon, Solid Earth, 6, 425-432, doi:10.5194/se-6-425-2015, 2015.

Pan, G. X. and Cao, J. H.: Karstification in Epikarst Zone: The earth surface ecosystem processes taking soil as a medium - the Yaji Karst experiment site, Guilin, Carsologica Sinica, 4, 289-296, 1999.

Perfect, E., Rasiah, V., and Kay, B. D.: Fractal dimensions of soil aggregate-size distributions calculated by number and mass, Soil Sci. Soc. Am. J., 5, 1407-1409, 1992.

Powers, J. S.: Changes in soil carbon and nitrogen after contrasting land-use transitions in northeastern Costa Rica, Ecosystems, 7, 134-146,2004.

Puget, P., Angers, D. A., and Chenu, C.: Nature of carbohydrates associated with water stable aggregates of two cultivated soils, Soil Biol. Biochem., 31, 55-63, 1998.

Puget, P., Chenu, C., and Balesdent, J.: Dynamics of soil organic matter associated with particle-size fractions of water-stable aggregates, Eur. J. Soil Sci., 51, 595-605, 2000.

Qi, L.: Soil water holding capacities and infiltration caracteristics of vegetation restoration communities in watershed, northwest Hunan, Scientia Silvae Sinicae, 4, 1-8,2007.

Qi, Y. C., Wang, Y. Q., Liu, J., Yu, X. X., and Zhou, C. J.: Comparative study on composition of soil aggregates with different land use patterns and several kinds of soil aggregate stability index, Transactions of the ASAE, 1, 340-347, 2011.

Rachman, A., Anderson, S. H., and Gantzer, C. J.: Influence of longterm cropping systems on soil physical properties related to soil erodibility, Soil Sci. Soc. Am. J., 2, 637-644, 2003.

Sainju, U. M., Terrill, T. H., and Gelaye, S.: Soil aggregation and carbon and nitrogen pools under rhizoma peanut and perennial weeds, Soil Sci. Soc. Am. J., 67, 146-155, 2003.

Shi, H.: Using transition matrix to evaluate stability of soil aggregates, Bull. Soil Water Conserv., 3, 91-95, 2006.

Stanchi, S., Falsone, G., and Bonifacio, E.: Soil aggregation, erodibility, and erosion rates in mountain soils (NW Alps, Italy), Solid Earth, 6, 403-414, doi:10.5194/se-6-403-2015, 2015.

Tan, Q. J., Song, T. Q., Peng, W. X., Zeng, F. P., Du, H., and Yang, G. R.: Stability and organic carbon characteristics of soil aggregates under different ecosystems in karst canyon region, Chinese J. Appl. Ecol., 3, 671-678, 2014.

Tang, F. K., Cui, M., Zhou, J. X., Yan, S., and Ding, F. J.: Difference analysis of soil organic carbon pool in different forestlands returned from farmlands in karst gorge area, Soil Sci. Water Conserv., 4, 1-7, 2014.

Tisdall, J. M. and Oades, J. M.: Organic matter and water-stable aggregates, J. Soil Sci., 33, 141-163, 1982.

Tyler, S. W. and Wheatcraft, S. W.: Application of fractal mathematics to soil water retention estimation, Soil Sci. Soc. Am. J., 53, 987-996, 1989.

Unger, P. W.: Aggregate and organic carbon concentration interrelationships of a Torrertic Paleustoll, Soil Till. Res., 42, 95-113, 1997.

Valmis, S., Dimoyiannis, D., and Danalatos, N. G.: Assessing interrill erosion rate from soil aggregate instability index, rainfall 
intensity and slope angle on cultivated soils in central Greece, Soil Till. Res., 80, 139-147, 2005.

Wei, Y. W., Su, Y. R., Chen, X. B., He, X. Y., Qin, W. G., and Wei, G. F.: Effects of human disturbance on soil aggregates content and their organic C stability in Karst regions, Chinese J. Appl. Ecol., 4, 971-978, 2011.

Wu, J. G., Zhang, X. Q., and Xu, D. Y.: Impact of land use change on soil carbon storage, Chinese J. Appl.Ecol., 4, 593-599, 2004.

Xiao, F. M., Fan, S. H., Wang, S. L., Xiong, C. Y., Yu, X. J., and Shen, Q. Z.: Mosbamboo plantation soil aggregate stability and its impact on carbon storage, J. Soil Water Conserv., 2, 131-134, 2008.

$\mathrm{Xu}$, E. Q. and Zhang, H. Q.: Characterization and interaction of driving factors in karst rocky desertification: a case study from Changshun, China, Solid Earth, 5, 1329-1340, doi:10.5194/se5-1329-2014, 2014.

Yan, F. L., Shi, Z. H., Cai, C. F., and Li, C. X.: Effects of topsoil aggregate stability on soil erosion at hill slope on ultisoils, Acta Pedologica Sinica, 4, 577-583, 2007.

Yan, X. and Cai, Y. L.: Multi-scale anthropogenic driving forces of karst rocky desertification in southwest China, Land Degrad. Develop., 2, 193-200, 2015.
Yang, P. L., Luo, Y. P., and Shi, Y. C.: Fractal features characterized by soil particle size distribution of the weight, Chinese Science Bulletin, 20, 1896-1899, 1993.

Young, R. A.: Characteristics of eroded sediment, Transactions of the ASAE, 23, 1139-1146, 1980.

Yuan, D. X., Liu, Z. H., and Lin, Y. S.: Karst dynamic system of China, Geological Publish Company, Beijing, 2002.

Zhang, X. B., Wang, S. J., and Cao, J. H.: Characteristics of water loss and soil erosion and some scientific problems on karst rocky desertification in Southwest China karst area, Carsologica Sinica, 3, 274-279, 2010 .

Zhou, Q.: Interaction between heavy metals and nitrogen fertilizers applied to soil-vegetable systems, B. Environ. Contam. Tox., 2, 338-344,2003.

Zhou, G., Zhao, H., Chen, G. Y., Xie, M. S., and Lai, Y.K.: Differential rule of soil anti-erodibility in different land-use of granite red soil region, Soil Water Conserv. China, 9, 27-29, 2008. 